\title{
THE PRESSURE OF GLOBALIZATION ON EDUCATIONAL EVOLUTION IN EMERGING ECONOMIES
}

\author{
Carmen Valentina Rădulescu, ${ }^{1, *}$, Mihaela Diana Oancea Negescu ${ }^{2}$, and Raluca Georgescu ${ }^{3}$ \\ ${ }^{1} \mathrm{PhD}$., Associate Professor, Bucharest University of Economic Studies, Romania \\ ${ }^{2} \mathrm{PhD}$., Associate Professor, Bucharest University of Economic Studies, Romania \\ ${ }^{2} \mathrm{PhD}$. Student, Bucharest University of Economic Studies, Romania
}

\begin{abstract}
Education is the path to sustainable evolution and acceleration of the catching up process in emerging economies. Without education there is no technological breakthrough, no increase in the created added value and also no improvement in the overall quality of life of a nation's inhabitants. This paper focuses on the added value created by education as a standalone process and also as a 2nd tier influencer of the economic meadow, with strong bifocal influence resulted in the adaptation and creation of economic policies targeted towards new educational standards. The main method of research used was documentary analysis that used both primary data from the literature, especially articles from journals indexed in international databases and from secondary data. The findings allowed us to draw conclusions on the expected course of action for education in the next period as well as the elements that can be included in the educational strategy. The pressure of globalization requires changes both economically, socially, politically and culturally and educationally. Changes are often accompanied by risks. Their debates have made it possible to identify future actions. The pressure of globalization requires changes both economically, socially, politically and culturally and educationally. Changes are often accompanied by risks. Their debates have made it possible to identify future actions for a sustainable and sustained development of emerging economies.
\end{abstract}

\section{Introduction}

Every curricular change implemented in the education system with more much or less necessary training (human resources, materials, time) has led to a number of specific realities, some with opportunities of opportunity, other difficulties [1]

Starting from the idea that any restructuring process must be based on a good knowledge of the state of the field of intervention concerned, a summary of the conclusions of the various researches and studies of the last years that have carried out the analysis of the curriculum Romanian [2,3]. Several such conclusions identify difficulties and problems at the general level of written curriculum, others focus on the analysis of the constraints that

*Corresponding author: carmen-valentina.radulescu@eam.ase.ro 
arise in the application of the curriculum in school practice or on some specific aspects (valorisation of non-formal / informal education in the curriculum, the development of communication skills at the level of compulsory education, curriculum specifics in vocational and technical education, school time as a component of the curriculum) [4]...

\section{Critical aspects of the general curriculum and its application}

Teachers and students, as well as parents, demand the curtailment of the curriculum, both by reducing the total number of hours of study in the curricula, as well as by specific interventions at the level of the curriculum [5].

The relationship between academic knowledge and the effective relevance of the information incorporated in school curricula and textbooks is deficient. Generally, applications of school knowledge are not found in everyday or productive daily life $[6,7,8]$. Students are not taught to work on projects, solve personal life problems, or relate to adultspecific issues.

School curricula and textbooks only partially respond to students' motivations, capacities and aptitudes. The content and applications proposed do not offer real opportunities to personalize educational approaches, and the investigated practices are still far from the idea of alternative sources of learning.

The curriculum of the school's decision as weight and variety is too narrow to provide flexibility and adaptation of the school's offer to its own needs and community demands. In school practice there are a number of difficulties regarding the selection and use of curricular products (school textbooks, didactic auxiliaries) [9]. There are a number of inconsistent and incoherent ways of developing school curricula. It is necessary to review the correlation between the reference objectives / specific competences and content. Inventories of learning activities and methodological suggestions need to be developed to provide real support for teachers in classroom work.

\subsection{The high share of school time in the students' daily budget.}

Teachers and students, as well as parents, show critical attitudes towards school timing: nearly two-thirds of those interviewed by said authors said the weekly school timetable is loaded or even highly loaded, generating tiredness among pupils [10]. This type of highly loaded program generates the reaction of both students and teachers to rejection.

The general conclusion seems to be that it is not normal for a student, regardless of his age, to work daily 10-12 hours, more than an adult at work. If it has at least 6 hours of course per day, the rest are for preparing the themes.

Over one third of the total working day students is dedicated to school related activities ( 8 hours and a half / day). The most demanding days are early week, which reveals a certain imbalance between weekly school rhythm.

The structure of the students' time budget reveals significant differences depending on the levels of study. The daily average of school time is higher for 8th grade students compared to 12 th grade students. Also, rural students, more involved in household activities, spend less time on school activities. In this case, there may be mentioned situations in which students lose their lessons due to the impossibility of reaching school, which means a long recovery time [11].

Homes for the home are assigned different time averages, depending on the resident environment, level of education or school subjects. Under these conditions, the development of extracurricular activities is little present among the pupils, the causes being varied: insufficient development of a specific offer a schools; lack of time from students for 
such activities, due to a too long budget allocated to school activities, insufficient motivation of pupils and teachers to organize and participate in such activities .

\section{Public policies that are currently active in education}

Regardless of the approach or methods used, the definition of a policy issue, once entered on the institutional agenda, is a fundamental step in making the process of identifying a most suitable and as widely accepted solution as efficient [12]. The "information dowry" that the problem is accompanied with since its sign-up and entry into the agenda can be more or less structured, varying considerably from the cases where the policy is already well-outlined, with possible solutions that also have tactics or regulations attached to cases where the problem consists of a heterogeneous set of discontents, ideas, elements of pressure contractors, the whole that needs a sustained effort to define a coherent definition [13].

Objectives should be formulated to be specific, measurable, and accessible, relevant and timed, which is identified in the literature by the SMART acronym [14]. Complying with the principles behind it provides the framework and the prerequisites for evaluating the results of public policy implementation [15].

A major success of politics in Romanian education, part of the emerging countries systems, was to meet the requirements of compulsory education [16] Over $90 \%$ of the school-age population began to learn on time, this percentage remaining at high levels throughout the compulsory cycle. However, the situation of Roma children is in contrast to the positive overall situation. Roma do not attend school and if they do, they are likely not to complete the education cycle. There is little data on Roma children, but discussions with local officials suggest the need for programs with a specific purpose (including data collection and policy formulation) for this group.

The provision of free education implies the absence of taxes in state education, free of charge for the compulsory cycle and for disadvantaged children from high school and vocational education (those children coming from families with incomes below the national average) and free medical and psychological assistance for all children at all levels from pre-school to high school [17]. The state budget finances the salaries of teaching staff at all levels. The budget of the state cooperates with local authorities in financing dormitories, canteens and outside activities, such as scientific, sporting, artistic and creative activities. Local authorities are responsible for the maintenance and repair of buildings, but can also help educational institutions in other ways. The new Law on Education stipulates that local authorities are responsible for materials procurement, repair, refinement and new investments, while MEN provides wage and manual funding.

Other state policies ensure the transport and accommodation of students who are not from the locality; including rail transport for pupils at daytime education. The state budget is also partly responsible for libraries, clubs and school camps, merit and social scholarships. Disabled children, orphans and those with special needs are also responsible for the state. This implies the existence of special schools and support for pupils and students in these categories attending educational institutions.

Other two priorities of the Romanian education system are to ensure the rights to cultural expression and to use the mother tongue and to organize educational activities in economically disadvantaged areas. The first priority finds expression in the rights of minorities (including groups with special educational needs) to be educated in their mother tongue (an area in which Romania is recognized as a world leader), incorporating the history and traditions of each minority in the curriculum and teaching materials, the provision of free textbooks for compulsory education in the mother tongue of each 
minority, regardless of its size (policy that gives rise to cost problems) and the training of teachers in the languages of national minorities.

This sensitivity does not, however, manifest in the case of the Roma. There seems to be a big difference in the numbers that indicate the frequency and outcomes of the Roma compared to the other children, but there are no clear data or programs to correct this situation. To solve the situation, special places for Roma were allocated, there are inspectors who monitor Roma education, along with the provision of language learning opportunities (in cooperation with nongovernmental organizations). The second priority, economically disadvantaged regions, has led to the creation of miniscule programs in isolated areas and the granting of additional income and benefits to teachers working in such areas.

\section{Possible solutions for increasing the efficiency of education}

At the beginning of the $21 \mathrm{st}$ century, there were social, technological and environmental changes [18]. The continued transition in the division of labor creates for all decision-makers the need to develop the evaluation processes of education and to analyze the ways of financing the institutional structures that have the role of dynamic adaptation to the environmental requirements.

A major change must be made at the level of the elements that define:

1. the organizational culture of each school;

2. the attitude towards lifelong learning and in all situations that arise and the one facing the learning and change of pupils, teachers and parents.

The education system is imposed on certain pupils that act at the level of the teachers, but also at the level of the curriculum.

Teachers should have:

- considering the initial and continuous training system;

- deficiency of professional insertion;

- maintaining integrated programs for teacher mobility and reconversion for other activities;

- effective use of all data on pupils' collectives for the continuous improvement of school performance;

- forming and developing technical abilities in the creative and complex use of digital information resources in the educational process;

- development of research, testing capabilities to maximize learning abilities;

- creating a high level of motivation for teachers;

- operationalization of a new teacher evaluation system.

At the level of the curriculum, the following vision is poor:

- constructing a curriculum that allows the mobility and flexibility of training paths for each beneficiary of education;

- the new framework plans allow for various types of exit from the education system, and at the end of the pre-university studies it is possible to be employed on the labor market or to continue the training through post-secondary or university study programs.

The culmination of the model is represented by the educational strategy, which includes the following objectives: 
1. declare the education system vital for national security;

2. the introduction of the national character of the education system;

3. stabilizing the state's interests in education, setting the objectives and duration of compulsory education, and the state's obligations in the education system.

Teachers (the main actors in the educational process) need the repositioning of the social status so that, along with the professional categories, they make models in a stimulating process.

\section{Conclusions}

The knowledge society calls for the promotion of educational models in which young people form critical, open, flexible and multidimensional personalities. This opens up a new place for effective communication culture, where training programs are diversified and defined through constructivist approaches centered on projects that seek to create motivating situations for the curiosity of young people.

In order to understand real-life messages, teachers and young people should focus on critical analysis of issues, promoting a multidisciplinary approach, where emphasis is placed on personal expression, reflexive and critical attitude, and encouragement the individual and group autonomy, the subjective judgment, the stimulation of imagination and the divergent thinking.

The major problem with the reform is the low level of the funds allocated by the Government for the maintenance and improvement of the educational infrastructure, the endowment with new materials and equipment and the payment of attractive salaries to the teachers. Other factors include weak institutional capacity to undertake reform, and resistance to change.

In order for the recovery of the educational system to be a success, it is necessary that education becomes a main topic of public debate, and good ideas will also have the support of those who will have to apply them.

\section{References}

1. G. Costache, C. V. Marinas, R. Igret, S. Burlacu, Internship in the HR DepartmentOrganizational and Individual Perspectives. Proceedings of the international management conference. Bucharest, Romania, 359-370 (2015)

2. S. Burlacu, D. Jiroveanu, IT Governance and Educational Ideal. Administratie si Management Public, 13, 73-82 (2009)

3. S. Burlacu, E-Faculty - Management Software Solution for Public Administration and Management Faculty, Administratie si Management Public, 8, 74-83 (2012)

4. E. Sharma, R. Tewari, Teaching sustainability through traditional wisdom: A conceptual framework for business studies. Current Science, 2, 236-244 (2017)

5. A. Androniceanu, S. Burlacu, Integration of Educational Technologies in Universities and students' perception Thereof. The International Scientific Conference eLearning and Software for Education. Washington, USA (2017)

6. S. Burlacu, Role of Training in the Knowledge Society. Proceedings of Administration and Public Management International Conference. Bucharest, Romania, 203-208 (2010)

7. S. Burlacu, Characteristics of knowledge-based economy and new technologies in education. Administratie si Management Public, 16, 114-119 (2011) 
8. S. Burlacu, D. Jiroveanu, The role of support open source systems to improve the quality of decisions in an educational institution in Romania. Proceedings of the 6th International Management Conference: Approaches in organizational management. Bucharest, Romania, 641-647 (2012)

9. M. M. Stoica, S. Burlacu, Concepts and Trends on E-Learning in Romania. The International Journal Of Engineering And Science (IJES), 6, 100-105 (2017)

10. E. Stonkute, J. Vveinhardt, W. Sroka, Training the CSR sensitive mind-set: The integration of CSR into the training of business administration professionals. Sustainability, 10, 1-14 (2018)

11. A.P. Haller, R. C. Butnaru, G. I. Butnaru, International Migrant Remittances in the Context of Economic and Social Sustainable Development. A Comparative Study of Romania-Bulgaria. Sustainability, 10 (2018)

12. V. Dudchenko, K. Vitman, K. (2018). Public Administration of Economic Development in the Context of the Institutional Theory. Baltic Journal of Economic Studies, 4, 139147 (2018)

13. M. Geissdoerfer, D. Vladimirova, D., S. Evans, Sustainable Business Model Innovation: A Review. Journal of Cleaner Production, 198(under review), 401-416 (2018)

14. F. Bran, C. Rădulescu, A. Bodislav, Waste Management and the Need for a Better Approach on Global Sustainability. The Impact of Climate Change on Our Life. (Springer, Singapore, 2018)

15. S. Burlacu, C. Gutu, F. O. Matei, Globalization-pros and cons. Calitatea, 19, 122-125 (2018)

16. F. Ioniţă, S. Burlacu, Public administration from romania in the knowledge society and e-learning. Proceedings of the Fifth "Administration and Public Management" international conference "Public institutions' capacity to implement the administrative reform process". Bucharest, Romania, 247-255 (2009)

17. V. Pelantova, E. Slaichova, The Contribution to the Integration of Management Systems Oriented to the Sustainable and TQM. Amfiteatru Economic, 19, 951-965 (2017)

18. D. A. Bodislav, F. Bran, L. Popescu, L., The Business-automated Data Economy Model. Quality-Access to Success, 19, 80-84 (2018) 